\title{
PARA INSPIRAR CONFIANÇA: CONSIDERAÇÕES SOBRE A FORMAÇÃO MORAL EM KANT
}

\author{
Mário Nogueira de Oliveira ${ }^{1}$
}

- RESUMO: Este artigo trata da formação moral do homem segundo Kant. Para ele, "o homem, afetado por tantas inclinações, é na verdade capaz de conceber a idéia de uma razão pura prática, mas não é tão facilmente dotado da força necessária para a tornar eficaz in concreto no seu comportamento". Deste modo, para implementar nossas máximas de comportamento Kant elabora seu estudo sobre a formação do homem para levá-lo a uma vida livre e moral.

- PALAVRAS-CHAVE: formação moral; ética kantiana; caráter.

O argumento de que os últimos escritos de Kant são frutos de um período de senilidade, junto à grande repercussão das obras anteriores à década de 1780, quase nos limitou a uma interpretação do pensamento ético de Kant em que estudos sobre antropologia, psicologia, biologia, história, educação ou qualquer outro de cunho empírico contribuíam pouco nos trabalhos sobre a aplicabilidade de sua ética. Textos de Kant que abordam questões acerca da natureza humana ou da história trazem para o debate da filosofia moral os dados empíricos que muitos dos seus seguidores excluíam, ao mesmo tempo em que alguns críticos lhe censuravam a ausência. Neste estudo mostramos como a questão da formação moral, tal como apresentada por Kant, reúne todos estes elementos em uma ética aplicável.

Em anos muito recentes contamos com alguns trabalhos que abordam a história, a antropologia e a pedagogia como constituintes de uma com-

1 Professor Adjunto do Instituto de Filosofia, Artes e Cultura da Universidade Federal de Ouro Preto (UFOP). 
preensão mais ampla da ética kantiana, apontando aí já os temas da formação moral e do caráter (cf. Munzel, 1999; Louden, 2000; Banham, 2003; Wood, 1999). Grande parte deles surgiu com a publicação do último volume de Kants gesammelte Schriften, em outubro de 1997, contendo mais de 1.500 páginas de anotações de estudantes dos cursos de Kant de Antropologia editadas por Reinhard Brandt e Werner Stark. Estas Preleções sobre antropologia deram novo impulso aos estudos kantianos (cf. Stark, 2003).

A atenção de Kant com as questões referentes à formação moral está presente já na Crítica da razão pura. Aí são tratados os efeitos nocivos e a desordem que uma má educação ou que a falta de cultivo em um homem introduz na sociedade ( $K r V$ A554-5; B582-3). Na Crítica da razão prática, Kant retoma a questão da formação moral ao abordar as instruções preparatórias necessárias para que um homem ainda inculto possa tornar-se receptivo ao interesse moral puro. Ao tratar da "metodologia da razão pura prática" (Methodenlehre), Kant afirma que ela constitui "o modo como se pode proporcionar às leis da razão prática pura acesso ao ânimo humano, de modo a provocar uma influência sobre as máximas do mesmo, isto é, como se pode fazer a razão objetivamente prática também subjetivamente prática" (KpV 269; Kant, 2002, p.239). Kant abre o caminho para suas obras que versam sobre a aplicação da sua ética no âmbito da educação do homem, como Doutrina da virtude (segunda parte da Metafísica dos costumes) e Sobre a pedagogia, anotando que quis referir-se somente às máximas mais gerais da "doutrina do método" acerca de uma cultura e exercícios morais. Kant conclui na passagem 288 (KpV 288; Kant, 2002, p.254-5) que sua segunda Crítica "é apenas um exercício preliminar" e que a multiplicidade dos deveres requer ainda determinações particulares para cada espécie deles, algo que implica ainda uma vasta tarefa posterior.

Segundo Kant, sua ética se divide entre a ética propriamente dita e a antropologia prática ou moral. Limitamo-nos aqui à segunda, uma vez que ela institui-se pelo direito e pela educação e, como dissemos, importa-nos aqui a questão da formação moral. Desta forma, é necessário entendermos a divisão proposta. Kant assim escreveu no Prefácio da Fundamentação da metafísica dos costumes:

Tanto a filosofia natural quanto a filosofia moral podem cada qual ter a sua parte empírica, pois aquela tem de determinar as leis da natureza como objeto da experiência, e esta, as da vontade do homem enquanto é afetada pela natureza; as primeiras, considerando-as como leis segundo as quais tudo acontece, a segunda, como leis segundo as quais tudo deve acontecer, mas ponderando também as condições pelas quais com freqüência não acontece o que devia acontecer.

Pode-se chamar empírica toda a filosofia que se baseia em princípios da experiência; mas a que apresenta as suas teorias derivando-as exclusivamente de princípios a priori denomina-se filosofia pura. Essa, quando é simplesmente formal, cha- 
ma-se Lógica; porém se limita a determinados objetos do entendimento, recebe então o nome de Metafísica.

Dessa forma, surge a idéia de uma dupla Metafísica, uma metafísica da Natureza e uma Metafísica dos Costumes. A Física terá, pois, sua parte empírica, mas também uma parte racional; da mesma forma a Ética, se bem que nesta a parte empírica se poderia chamar especialmente antropologia prática, enquanto a parte racional seria a Moral propriamente dita. (MdS BA III - IV; Kant, 1988, p.13-4)

Ele vai adiante ressaltando a necessidade de uma antropologia prática para nos tornar aptos a aplicar a moral propriamente dita através da nossa faculdade de julgar, que, por sua vez, é aprimorada pela experiência. Precisamos da antropologia prática para que sejamos capazes de acolher em nossa vontade, pela via da educação e do exercício, as leis morais em seus princípios e também assegurarmos sua eficácia, seja pelo aprendizado na nossa formação moral, seja pela força externa do direito. Uma vez que Kant assegura que "o homem, afetado por tantas inclinações, é na verdade capaz de conceber a idéia de uma razão pura prática, mas não é tão facilmente dotado da força necessária para a tornar eficaz in concreto no seu comportamento" (MdS BA IX, X 389; Kant, 1988, p.16), devemos, então, considerar nossas máximas de comportamento, nossa subjetividade, como cultiváveis.

Na Introdução à Metafísica dos costumes, Kant volta a esclarecer sobre a função e especificidade da antropologia prática, agora chamada de antropologia moral. Kant lhe chama de "o outro membro da divisão da filosofia prática" (MdS 417; Kant, 2003, p.59) e ressalta que ela se ocupa do desenvolvimento, da difusão e do fortalecimento dos princípios morais, tanto na educação escolar quanto na instrução do povo. A antropologia moral é indispensável, mas não deve preceder uma metafísica dos costumes ou ser a esta mesclada. Para Kant, seu lugar é paralelo, mas orientada pelos preceitos dados a priori somente na razão pura onde está enfocada a Metafísica dos costumes. Nas Preleções sobre ética, especificamente nas anotações feitas pelo seu aluno C.C. Mrongovius, há outra elucidação:

A metafísica dos Costumes, ou metaphysica pura, é apenas a primeira parte da moralidade; a segunda parte é a philosophia moralis appliccata, antropologia moral, à qual os princípios empíricos pertencem. (...) A filosofia prática geral é propedêutica. A antropologia moral é a moralidade aplicada ao homem. Moralia pura é baseada em leis necessárias, e assim ela não pode ser fundamentada na constituição particular do homem, e as leis baseadas nisso ficaram conhecidas na antropologia moral sob o nome de ética. Na filosofia prática geral, a metafísica dos costumes, ou metaphysica pura, é também apresentada em um modo mesclado. (MdS 599; Kant, 1997, p.226)

Estas referências à antropologia moral, como podemos depreender, implicam o tema da educação onde está inserida a questão da formação moral. Seu maior texto de Kant sobre o assunto é um conjunto de preleções intitu- 
lado Sobre a pedagogia, embora possamos contar com outras boas fontes para esta específica pesquisa. ${ }^{2}$

Quando Sobre a pedagogia foi editado, Kant já tem bem amadurecida a concepção de que a organização social da Alemanha está bastante longe dos ideais do Esclarecimento devido ao despotismo político e à falta, no sistema educacional do seu país, de princípios universais advindos de uma moralidade apriorística e que, aplicados no processo educativo, levassem os homens à liberdade e à felicidade. É, portanto, inserido neste pensamento que Kant lança uma pergunta que até hoje nos faz pensar: "Como poderíamos tornar os homens felizes, se não os tornamos sábios e morais?" (UP 451; Kant, 1999, p.28). Para isso é preciso que sejam educados e, desta forma, afirma seu propósito:

com a educação presente, o homem não atinge plenamente a finalidade da sua existência. (...) Podemos trabalhar num esboço de educação mais conveniente e deixar indicações aos pósteros, os quais poderão pô-las em prática pouco a pouco. (idem 445; idem, p.17)

É importante ressaltar que, como um representante do Iluminismo, Kant nunca buscou negar o lugar de um estudo empírico do homem na sua ética. Ele criticou prontamente outros moralistas que ignoraram a natureza humana. Nas Preleções sobre ética (AK XXVII 244) afirma:

Alguém pode, realmente, considerar a filosofia prática mesmo sem a antropologia, ou sem o conhecimento sobre o agente, apenas isto é meramente especulativo, ou uma idéia. Assim, o ser humano deve pelo menos ser estudado apropriadamente. De outro modo, a filosofia moral torna-se repetições de regras que todos já conhecem, e que nos imprime muito tédio... e as pregações nos púlpitos são vazias em seu conteúdo, se o pregador não observa simultaneamente a humanidade.

Kant possuía um genuíno interesse pela educação dos homens do seu tempo. Sabemos que entre seus leitores estavam pessoas educadas e estudiosas da ciência newtoniana e, obviamente, outros filósofos (cf. MdS 40910; KpV 24). Entretanto, o mais importante grupo a quem Kant se dirigia era

2 Uma destas fontes que complementa de modo substantivo sua teoria educacional pode ser encontrada nas seções de Methodenlehre (Doutrina do Método) da Crítica da razão prática e da Metafísica dos costumes. Considerações arquitetônicas assim como práticas acadêmicas do seu tempo levaram Kant a dividir suas três críticas em Elementarlehre (Doutrina dos Elementos) e Methodenlehre (Doutrina do Método), e a segunda metade da Metafísica dos costumes (Doutrina da virtude) é dividida de modo semelhante. Várias das Preleções de Lógica também estão divididas assim. Outras boas fontes são os dois pequenos ensaios sobre o Instituto Philanthropinum e o recentemente divulgado, Nachricht (Anúncio do programa das suas preleções do semestre de verão de 1765-1766) (303-13). 
formado por pessoas comuns relativamente não-educadas. Ele teve grande respeito pelas conviç̧ões morais pré-filosóficas das pessoas, e de fato baseou sua análise inteira da moralidade naquilo a que se refere como a "consciência moral comum". Kant acreditou que as pessoas realmente possuem uma noção, mesmo que pouco clara, do que seja a moralidade, quando não a possuem de modo mais límpido. Para Kant, o principal problema que tais pessoas enfrentavam consistia na dificuldade em persistir nos seus ideais morais. Visando contribuir para esta questão específica, buscou formular a norma moral definitiva de modo tão claro e preciso quanto lhe fosse possível. Além disso, visou oferecer alguns conselhos sobre o que é político e moralmente certo ou errado e também buscou oferecer um esclarecimento a toda uma geração.

Ao reconhecer a preferência dos seus contemporâneos por uma filosofia prática popular sobre uma metafísica da moral, Kant aceita a provocação. Entretanto, acredita que a moralidade deve ser qualificada pelos "princípios da razão pura" articulados de modo que a doutrina moral seja "baseada na metafísica". Assim, assegura que mesmo no uso prático popular, especialmente naquele da instrução e formação moral, seria impossível fundar a moral nos seus princípios genuínos e assim cultivar bons caracteres morais sem os princípios da razão pura. Isso porque a moralidade para os seres humanos é o resultado pretendido de um processo educacional extensivo uma vez que "atrás da educação repousa o grande segredo da perfeição da raça humana" (UP 444; Kant, 1999, p.16). A própria moralidade, ao menos no que concerne aos seres humanos, pressupõe a educação. A moralidade não pode simplesmente ser um produto causal da educação, mas ela pressupõe a educação, uma vez que "por natureza o ser humano não é um ser moral em absoluto." (idem 492; idem, p.95)

Em Sobre a pedagogia, Kant descreve os estágios e divisões da educação na qual a formação moral estará inserida. O primeiro estágio é o cuidado (idem 441; idem, p.11) que é uma parte da "Educação Física" oposta à "Educação Prática", e forma aquela parte da educação "que o ser humano tem em comum com os animais" (idem 455; idem, p.34). Uma vez que Kant abre Sobre a pedagogia anunciando que o ser humano "é a única criatura que precisa ser educada" (idem 441; idem, p.11), existe realmente um sentido no qual o cuidado também se coloca fora dos parâmetros da educação tal como o próprio Kant, de início, a constrói.

O segundo estágio da educação é a disciplina ou o treinamento. Como o cuidado, a disciplina também é entendida como um estágio preliminar da própria educação. Segundo Kant, "a disciplina transforma a animalidade em humanidade" (ibidem; idem, p.12). Mas, sabemos que "transformar" não significa "erradicar". Na realidade, disciplinar "significa procurar evitar que a animalidade cause danos à humanidade. (...) A disciplina é, portanto, mera- 
mente domar a selvageria" (UP 449; idem, p.25). Em um sentido mais amplo, essa tarefa é compartilhada com o que Kant chama de "cultura negativa" ou "libertar a vontade do despotismo dos desejos" (KU, 433; Kant, 1995, p.294-5).

O terceiro estágio, geralmente chamado de "cultura". Devemos ressaltar que, algumas vezes, os termos "formação" e "cultura" são usados de forma indiferenciada em Sobre a Pedagogia, e este estágio inclui uma variedade de processos mais específicos tais como a instrução (UP 441; Kant, 1999, p.11), o ensino (idem 449; idem, p.24-5) e a orientação (idem 452; idem, p.29-30). Kant freqüentemente faz uma distinção adicional entre a cultura geral e "um certo tipo de cultura, que é chamada de civilização" (idem 450; idem, p.26). A "civilização" tem como objetivo não apenas a habilitação, mas também a prudência e assim, representa um estágio mais alto. "Toda a prudência pressupõe habilidade. A prudência é a faculdade de alguém usar suas habilidades de um modo socialmente efetivo para alcançar seus objetivos" (idem 455; idem, p.35). Ao final da Antropologia, ele afirma:

o resumo da antropologia pragmática com referência ao destino do ser humano e as características da sua educação é o seguinte: o ser humano é destinado através da sua razão a estar em sociedade com outros seres humanos e a se cultivar, a se civilizar e a se moralizar nessa sociedade através das artes e das ciências. (A 324; Kant, 1996, p.240-1)

A civilização conduz ao último estágio da educação que é a moralização. A moralização, tal como posta em Sobre a pedagogia, não pode ser uma simples adição da cultura e da civilização. Ela envolve também uma passagem para o reino da liberdade que, logicamente, pressupõe os passos preparatórios da cultura e da civilização. Para Kant, a humanidade está ainda muito distante do estágio final da moralização, pois "vivemos em um tempo de treinamento disciplinar, de cultura e de civilização, mas de modo algum em um tempo de moralização." (UP 451; Kant, 1999, p.28)

Mas qual é o grande fim da moralização? Para Kant, em última instância, o fim da moralização e, portanto, de toda a educação moral é a formação do caráter do homem. O primeiro esforço da cultura moral deve ser lançar os fundamentos do caráter. Para ele, o caráter consiste no hábito de agir segundo certas máximas. Estas são, em princípio, as da escola e, mais tarde, as da humanidade. Em Sobre a pedagogia, Kant mostra que quando se quer formar o caráter das crianças, urge mostrar-lhes em todas as coisas um certo plano e certas leis, que elas devem seguir fielmente. Isto porque Kant acredita na formação moral como fomentadora da confiabilidade entre os homens. Para ele, "os homens que não se propuseram certas regras não podem inspirar confiança; não sabemos como nos comportar com eles" (idem 481; idem, p.77). Kant está certo, entretanto que o entendimento pleno do 
estudante sobre o agir por dever somente será possível com o passar dos anos e, assim, sua obediência, a cada dia, será aperfeiçoada.

Para formar um bom caráter, é preciso domar as paixões. Mas, não as erradicar. Para aprender a se privar de alguma coisa são necessárias coragem e uma certa inclinação. É preciso acostumar-se às recusas e à resistência. Mas não é só com abstinências que se forma um caráter. Kant assegura que este é formado também na sociabilidade. Ele diz que o educando deve manter boas relações de amizade uma vez que apenas um coração contente é capaz de encontrar prazer no bem (idem 485; idem, p.82). Segundo Kant, "a etapa suprema da educação é a consolidação do caráter que consiste na resolução firme de querer fazer algo e colocá-lo realmente em prática." (idem 487; idem, p.87)

Esta ênfase em fundar solidamente o caráter de alguém está presente tanto em passagens de A religião nos limites da simples razão quanto em Sobre a pedagogia. Assim, esse emprego do conceito de "formação moral" é direto e claro: Kant acredita que há um tipo de educação que pode ultrapassar as causas naturais e as circunstâncias temporais e chegar ao modo do agente pensar e fundar seu caráter moral. A educação moral é bem sucedida à medida que alcança este objetivo.

Kant busca um método educativo que pudesse atingir tais objetivos. $\mathrm{O}$ que é necessário é um método de educação prática que produza um genuíno efeito moral no coração (cf. KpV 157; Kant, 2002, p.142-3). Nos dois pequenos ensaios sobre o Instituto Philanthropinum (cf. nota 2), Kant apresenta seu aval a uma experiência audaciosa na qual "a educação se estabelece de um modo radicalmente novo de acordo com o método genuíno". Um tal método não deve (como Kant pensa ser o caso com todos os demais institutos educacionais) "trabalhar contra a natureza". Ao invés disso, o método deve ser "sabiamente retirado da própria natureza e não copiado sem originalidade de um velho hábito e de épocas quando não houve experimentos". Então, o bem ao qual a natureza propiciou a predisposição pode ser extraída dos seres humanos, e "nós, criaturas animais", seremos tornados seres humanos através da educação apropriada (cf. UP 443; Kant, 1999, p.14-5).

O objetivo final é que o estudante compreenda que "a norma e a instrução repousam somente na sua razão". Com o processo educativo, sua própria razão vai ensinar-lhe aquilo que você tem que fazer e diretamente lhe comanda fazer" (MdS 481; Kant, 2003, p.320). Por isso, para os jovens a quem isso ainda não é possível, a educação é imprescindível para sua liberdade. ${ }^{3}$

3 As subdivisões dos métodos que Kant apresenta para ensinar ética não são inteiramente originais. Segundo ele, se a doutrina da virtude deve ser apresentada como uma "ciência" ela deve também ser sistemática e possuir sua "didática ética" que é o termo amplo que Kant usa para os métodos de ensino (Metafísica dos costumes, 478): a apresentação pode tanto ser tanto acroamática (do grego akroamai, ouvir) em que todos, exceto o professor, são meros ouvintes, ou erotemá- 
OLIVEIRA, M. N. de. To inspire trust: considration about the moral formation in Kant. Trans/Form/Ação, (São Paulo), v.29(1), 2006, p.69-77.

- ABSTRACT: This article treats the concept of moral formation according to Kant. He sustains that "man, affected by many inclinations, is able to conceive the idea of a pure practical reason, but is not equally able to make it effective in his behavior". So, in order to improve our maxims of behavior Kant elaborates his study on man education in order to lead him to freedom and morality.

- KEYWORDS: moral formation; kantian ethics; moral character.

\section{Referências bibliográficas}

BANHAM, G. Kant's Practical Philosophy: From Critique to Doctrine. N. York, Palgrave MacMillan, 2003.

JACOBS, Brian \& KAIN, Patrick (ed). Essays on Kant's Anthropology. Cambridge, Cambridge University Press, 2003.

KANT, I. Kant in Kontext Werke auf CD-ROM. Karsten Worm - InfoSoftWare, 1996.

Anthopology from a pragmatic point of view. Translated by Lyle Dowdell.

Carbondale \& Edwardsville, Southern Illinois University Press, 1996.

. Antropologia en Sentido Pragmático. Trad. por José Gaos. Madrid, Alian-

za Editorial, 1991.

. Crítica da Razão Pura. Trad. Manuela P. dos Santos \& Alexandre F. Moru-

jão. Lisboa, Fundação Kalouste Gulbenkian, 1989.

. Crítica da Razão Prática. Trad. por Valério Rohden. São Paulo, Martins

Fontes, 2002.

. Crítica da Faculdade do Juízo. Trad. por Valério Rohden e António Marques. Rio de Janeiro, Forense Universitária, 1995.

Fundamentação da Metafísica dos Costumes. Trad. por Paulo Quintela. Lisboa, Edições 70, 1988.

. Lectures on Ethics. Edited by Peter Heath \& J. B. Schneewind. Transla-

ted by Peter Heath. Cambridge, Cambridge University Press, 1997.

Lógica. Trad. Guido de Almeida. Rio de Janeiro, Tempo Brasileiro, 1992.

A Metafísica dos Costumes. Trad. Edson Bini. São Paulo, Edipro, 2003.

tica (do grego eromai, perguntar) em que o professor pergunta a seus alunos aquilo que lhes quer ensinar". O método erotemático é, por sua vez, subdividido no "modo dialógico" e no "modo catequético" de ensino. No modo dialógico, o professor questiona a razão do estudante, e no modo catequético, o professor meramente questiona a memória do estudante (Metafísica dos costumes, 78). No método dialógico, o professor e o estudante alternam perguntas e respostas entre si. De um modo alternativo, com o método socrático "o estudante questiona o professor (que de fato ainda é o estudante)". 
KANT, I. Sobre a Pedagogia. Trad. Francisco C. Fontanella. Piracicaba, Unimep, 1999.

Über Pädagogik. In: Werkausgabe XII. Königsberg, F.Nicolovius, 1803.

STARK, Werner. "Historical Notes and Interpretative Questions about Kant's Lectures on Anthropology". In: Brian Jacobs \& Patrick Kain (ed). Essays on Kant's Anthropology. Cambridge, Cambridge University Press, 2003.

LOUDEN, R.B. Kant's Impure Ethics: From Rational Beings to Human Beings. New York, Oxford, Oxford University Press, 2000.

MUNZEL, G. F. Kant's Conception of Moral Character. Chicago, The University of Chicago Press, 1999.

WOOD, A.W. Kant's Ethical Thought. Cambridge, Cambridge University Press, 1999.

Artigo recebido em 01/06; aprovado para publicação em 05/06. 